\title{
A degree of professionalism
}

\section{There's a growing career path for students who like science, but don't want to be academics.}
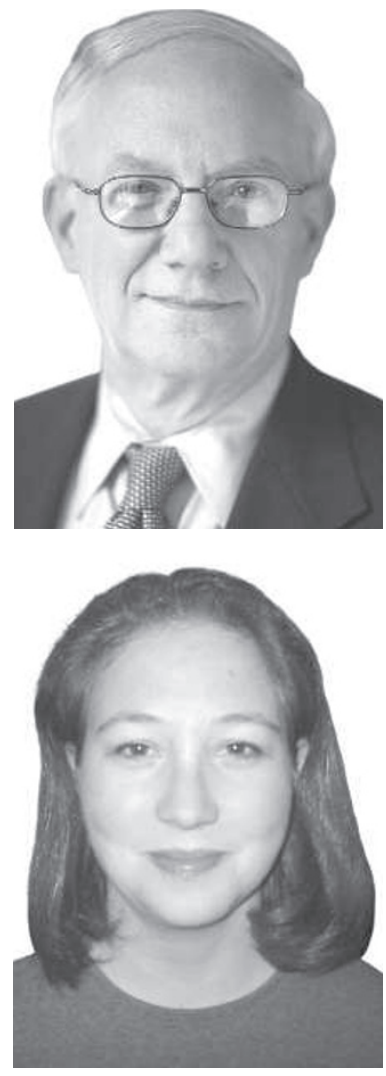

Michael S. Teitelbaum \& Virginia T. Cox
Concerns about the adequacy of a country's scientific workforce feature in nearly all public discussions about 'innovation' and 'competitiveness'. Recently, for example, a wave of reports from industry associations and scientific associations called for substantial increases in public funding to expand the pipeline that ends with the production of newly minted $\mathrm{PhD}$ scientists.

The disparities in the claims are truly astonishing - all the way from shortages to oversupply of graduate scientists; and from claims by employers that they cannot find the recruits they need, to claims by junior scientists that they face dispiriting employment opportunities.

The data are weak, anecdotal and often based on problematic labour-market forecasts.

Typically, they do not account for disciplinary differences in supply and demand (see Nature 445, 121, 124; 2007).

There is also concern about the content of graduate education in science. Employers often comment that scientists who want to work outside academia need more than strong scientific backgrounds. Graduate students, they say, should also seek skills in marketing, business and communication.

A fraction of science $\mathrm{PhDs}$ may indeed find additional professional training useful, again varying greatly by discipline and sector of employment. But a large proportion of those in scientific occupations outside academia do not have $\mathrm{PhDs}$, and recruiters in many industries say that a large fraction of their recruits do not need PhDs, and may even be better off without them.

It is for such career paths, in science but outside academe, that professional science masters (PSM) degrees have been explicitly designed (see www. sciencemasters.com). There are now more than 100 such degree programmes, developed by science faculty at more than 50 US universities (in the interests of full disclosure, we should add that the Sloan Foundation has provided start-up grants to many of these programmes). Similar degree programmes are emerging in other countries.

These degrees are by no means clones of one another, but typically they are two-year 'science-plus' graduate degrees focusing primarily on courses, with less attention to lengthy research projects. Most are designed and taught by graduate science departments, and the coursework required often includes the bulk of the courses required of $\mathrm{PhD}$ candidates.

The 'plus' elements focus on intensive coursework and realworld experience in the business

\section{"Recruiters in many industries say that a large fraction of their recruits do not need PhDs, and may even be better off without them."}

skills mentioned above - and such coursework attracts interest from $\mathrm{PhD}$ candidates as well. In addition, PSM programmes typically have close relationships with local employers seeking recruits with skills in science, business and management.

So far, at least, PSM programmes have given graduates attractive new pathways to science and engineering careers outside academe. Testimonials from PSM graduates suggest that early cohorts have found very appealing employment opportunities, better than baccalaureate holders and often as good as PhDs. Still, it is too early to know for sure how successful PSM graduates ultimately will be - many PSM courses are new and the number of graduates is relatively small, so it will take several more years before it is clear how their careers have progressed after initial employment.

The PSM is not in competition with the $\mathrm{PhD}$. On the contrary, it is designed for those who are good at, and enthusiastic about, science and mathematics, but who do not wish to pursue the $\mathrm{PhD}$-plus-postdoc route required for a job in academic research. Put another way, many undergraduates and graduate students deterred by the prospects for traditional careers in science may find themselves drawn to the PSM pathway.

If so, the availability of such a graduate career pathway might increase retention of freshmen in science and mathematics. According to the US National Science Board's 2004 figures, about half of the students who begin university intending to major in these subjects shift to other disciplines.

Sceptics might argue that PSM degrees run counter to the interests of research universities and their research-oriented faculty members - that $\mathrm{PhD}$ students are needed as research assistants for grant-supported research, and as teaching assistants to enable faculty members to devote more time to their externally funded research. For some institutions and some faculty members, such concerns may be justified.

Yet many institutions and science faculty members see one of their responsibilities as providing high-quality graduate science education for the nonacademic workforce. This kind of perspective seems especially strong at leading public research universities, and at 'mastersfocused' and comprehensive universities with strong science traditions.

Michael S. Teitelbaum is vicepresident and Virginia T. Cox is programme associate, Alfred P. Sloan Foundation, 630 Fifth Avenue, New York, New York 10111. Comments welcome to teitelbaum@sloan.org 